treated each year in a unit of six beds. Generally at any one time two infants are on curare and I.P.P.V., two are being weaned from the ventilator, and two are in the process of being detubated. The infants stay in the wand from six to eight weeks.

the single most important contributory factor towards success in treatment is the constant care and attention by the doctor in charge. Until the method is perfected and the nursing staff are familiar with the hazards, the doctor must visit the child every four hours. If he cannot sleep in he must see the child at midnight and again first thing in the morning. The doctor must make himself fully familiar with the techniques, particularly of physiotherapy and suctioning, after which assistants and registrars can be trained to take over part of the care. The same applies to the nursing staff, who must be trained in sufficient numbers to provide full 24 -hour cover. It is useless to try to treat these children if an untrained nurse is expected to take over the care of a child who can die in five minutes should anything go wrong. Nevertheless, high praise is due to the nursing staff who are not trained nurses, but nurseaides; care and attention and dedication has been largely responsible for the good results.
ADDENDUM.- Recently a positive end expiratory pressure of $5 \mathrm{~cm}$ water has been used with ventilation of these infants (Voss, 1973). At this early stage the results seem promising, with the absence of atelectasis of the upper lobes, reduction in respiratory infection, and a great improvement in the shape of the chest. This expiratory pressure is easily obtained by letting the end of the expiratory tube open under $5 \mathrm{~cm}$ of water.

We thank the ear, nose, and throat surgeons, especially $\mathrm{Mr}$. J. Marais, for doing the tracheostomies, and the medical superintendent of the Red Cross War Memorial Children's Hospital for permission to publish.

Requests for reprints should be addressed to: Dr. M. D. Bowie, Department of Paediatrics, Medical School, University of Cape Town, Mowbray, Cape, South Africa.

\section{References}

Smythe, P. M. (1967). Lancet, 1, 335.

Smythe, P. M. (1964). Fournal of Pediatrics, 65, 446.

Smythe, P. M., and Bull, A. (1959). British Medical fournal, 2, 107.

Smythe, P. M. (1963). British Medical fournal, 1, 565.

Sykes, M. K. (1960). British fournal of Anaesthesia, 32, 256.

Voss, T. J. V. (1973). South African Medical Fournal, 47, 761.

\title{
Can I Have an Ambulance, Doctor?
}

\section{T. C. BEER, E. GOLDENBERG, D. S. SMITH, A. STUART MASON}

British Medical fournal, 1974, 1, 226-228

\section{Summary}

In a study of the ambulance service to an outpatient physiotherapy centre in an urban area over half of the palients were aged over 65, a quarter made at least three visits to the centre weekly, and the average travel and waiting times for all patients was about two-and-a-half hours. There was a direct relation between distance from home to the centre and travelling time for morning but not afternoon attenders. A second survey after some changes in the transport arrangements showed some relatively small reductions in overall travelling and waiting time. It is concluded that even under favourable conditions an important side effect of outpatient physiotherapy is the probable fatigue and anxiety generated by ambulance travel.

\section{Introduction}

The study by the Organisation and Method Group of the Department of Health ${ }^{1}$ on outpatient departments and the ambulance service showed that over half of all outpatient ambulance journeys were made by patients attending physiotherapy departments. The report suggested that any test of the efficiency of the transport service for outpatients must therefore be concentrated on the arrangements for patients attending these departments and other frequent ambulance users such as fracture clinics.

Northwick Park Hospital, Harrow, Middlesex HA1 3UJ

T. C. BEER, M.B., M.R.C.P., Senior Registrar

E. GOLDENBERG, S.R.N., Research Assistant

D. S. SMITH, D.PHYS.MED., F.R.C.P., Consultant Physician

A. STUART MASON, M.B., M.R.C.P., Member of scientific staff, M.R.C and D.H.S.S. Epidemiology and Medical Care Unit
In view of this and because of the increasing emphasis on rehabilitation services we have studied the transport arrangements for patients attending the Harrow Physical Treatment Centre, which is in effect the outpatient physiotherapy department of Northwick Park Hospital.

\section{Organization}

Some 800 attendances are made at the centre each week. Twelve per cent. of the patients are brought by ambulance; the hospital car service is not used for this purpose.

Outpatient physiotherapy is ordered by a hospital doctor working in one of the hospitals in the Northwick Park group. There is no direct general-practitioner access to physiotherapy services. When physiotherapy is ordered a note is made on whether ambulance transport will be required. This information is passed to the hospital transport officer, who orders an ambulance to take the patient to the centre for the first day of treatment. Subsequently transport is ordered by a clerk at the centre, who sends a block booking to the ambulance service for the duration of the course of treatment, as ordered by the doctor.

Transport is cancelled only by a doctor, who does not ordinarily review the patient until the treatment has been completed. Thus even if the patient recovers sufficiently during treatment to make his own way to the centre the ambulance will continue to call. Contact between centre and ambulance control occurs only when a new patient has to be "block booked" or a patient has had to cancel his treatment: it does not take place every day.

Ninety five per cent. of patients walk well enough to be collected in a single-handed, eight-seater ambulance which during the day is confined to serving the centre. Each evening the driver receives from ambulance control a list of the patients he is to pick up next day. He does three or four rounds a day depending on how many patients require treatment and their place of residence.

Patients are told that the ambulance will call sometime after 8.30 a.m. (all morning attenders) or after 1.30 p.m. (all afternoon 
attenders). The first patients are collected soon after 8.30 and arrive at the centre between 9.15 and 9.45 a.m. The second group arrive between 10.30 and 11 a.m., though they too have been waiting since 8.30. Treatment is started immediately the patients arrives and lasts about 30 minutes. After these patients are taken home the driver breaks for lunch. In the afternoon all the patients arrive between 2 and 2.30 p.m., as usually only one collection is made.

\section{Methods}

In 1972 an observer from Northwick Park Hospital spent two five-day periods (Monday to Friday) at the centre, one in September and another in November (first survey). Each patient arriving for the morning or afternoon session was interviewed, and asked about his treatment, the date of first attendance at the centre, the number of attendances a week, and the time of his appointment. In addition he was asked about the time he had been told to expect the ambulance to pick him up at home and when he was actually collected. These times were recorded together with the time of arrival. On completion of treatment the patients were handed a stamped addressed postcard and asked to record the time at the end of their treatment, the time of departure of the ambulance from the centre, and the time of their arrival home. Complete information was received for $154(86 \%)$ of the 179 attendances. Using the same methods we studied a further five-day period (second survey) in August 1973 after the results of the first survey had been discussed with the ambulance staff.

\section{Results}

Altogether 87 patients who came by single-handed ambulances made 179 attendances $(12 \%$ of the total) during the first survey. Of these patients $74 \%$ were 60 years or over. There were more women $(59 \%)$ than men $(41 \%)$, the difference being due to the greater number of women aged 70 or more.

There were no significant differences in waiting and travelling times between the two weeks of the first survey, which were therefore considered together. Three or more visits a week were made by $25 \%$ of the patients (table I). Altogether $33 \%$ of the morning attenders and $75 \%$ of the afternoon attenders waited at home for an ambulance for an hour or more (table II). Total travelling time was also longer in the afternoon; $71 \%$ of afternoon attenders travelled for over an hour, compared with $36 \%$ of attenders in the morning. The situation was reversed with

TABLE I-Frequecny of Attendance by Patients brought by Single-handed Ambulance During First Survey

\begin{tabular}{l|r|r|r|r|r|c}
\hline $\begin{array}{l}\text { No. of attendances } \begin{array}{c}\text { a week } \\
\text { No. of patients }\end{array} \\
\text { Nate }\end{array}$ & 26 & 39 & $\underbrace{17}$ & 1 & 4 & 8 \\
\hline
\end{tabular}

TABLE III-Mean Times (Ranges in Parentheses) spent by Patients waiting and travelling (in Minutes)

\begin{tabular}{|c|c|c|c|c|}
\hline Session & $\begin{array}{l}\text { Waiting at } \\
\text { Home }\end{array}$ & Travelling & $\begin{array}{l}\text { Waiting at } \\
\text { Centre }\end{array}$ & Total \\
\hline $\begin{array}{l}\text { Morning } \\
\text { Afternoon }\end{array}$ & $\begin{array}{l}49(0-150) \\
61(0-130)\end{array}$ & $\begin{array}{c}\text { First Survey } \\
54(15-125) \\
70^{*}(15-145) \\
\text { Second Survey }\end{array}$ & $\begin{array}{l}55+(5-160) \\
33(0-120)\end{array}$ & $\begin{array}{l}158(80-290) \\
164+(88-255)\end{array}$ \\
\hline $\begin{array}{l}\text { Morning } \\
\text { Afternoon }\end{array}$ & $\begin{array}{l}50(0-110) \\
49(30-80)\end{array}$ & $\begin{array}{l}54(15-125) \\
53 *(20-110)\end{array}$ & $\begin{array}{l}38+(0-93) \\
30(5-120)\end{array}$ & $\begin{array}{ll}142 & (62-230) \\
132 & (85-195)\end{array}$ \\
\hline
\end{tabular}

TABLE IV-Proportions of Patients (given in Percentages) living Stated Distances from Physical Treatment Centre. First Survey

\begin{tabular}{c|c|c|c}
\hline \multirow{2}{*}{ Distance in Miles } & \multicolumn{2}{|c|}{ Time of Attendance } & \multirow{2}{*}{ Total } \\
\cline { 2 - 3 } & Morning & Afternoon & \\
\hline $0-$ & 17 & 21 & 18 \\
$1-$ & 30 & 26 & 29 \\
$2-$ & 36 & 38 & 37 \\
$3-$ & 9 & 9 & 9 \\
4 & 8 & 6 & $7\} 16$ \\
\hline Total & 100 & 100 & 100 \\
\hline
\end{tabular}

Note: 1 mile $=1.6 \mathrm{kms}$.

TABLE $\mathrm{v}-$ Relation between Time spent Travelling and Distance from Home to Physical Treatment Centre. First Survey

\begin{tabular}{l|c|c}
\hline \multirow{2}{*}{ Distance in Miles } & Average Journey Time (min) \\
\cline { 2 - 3 } & Morning & Afternoon \\
\hline $0-$ & 45 & 73 \\
$1-$ & 45 & 73 \\
$2-$ & 63 & 64 \\
$3-$ & 68 & 105 \\
\hline & 55 & 70 \\
\hline \multicolumn{2}{c}{ Total } & 51 \\
\hline Correlation coefficients between distance and journey time for $($ a $)$ morning iourneys \\
$+0.37(\mathrm{P}<0.001)$ and $(b)$ afternoon journeys $+0.15(P>0.1)$.
\end{tabular}

regard to waiting time at the centre after treatment: $44 \%$ of the morning attenders waited at least an hour compared with $15 \%$ of the attenders in the afternoon (table III). As only one collection was made in the afternoon the ambulance was more readily available than in the morning for the journey home.

Only $16 \%$ of the patients were picked up 3 miles $(4.8 \mathrm{~km})$ or more away from the centre (table IV). For the morning attenders there was a positive relation between times spent travelling and distance from the centre (table V), but this relationship did not hold for the afternoon attenders. A possible explanation may be that in the afternoon only one collection is made, so that there may be less scope for planning ambulance journeys to the advantage of patients living nearest the centre.

In the second survey 38 patients making 82 attendances were questioned. The mean waiting time at the centre in the morning and the mean travelling time in the afternoon were both significantly less in the second survey compared with the first (table III; $P<0.001$ and $P<0.05$ respectively), but otherwise results for the two surveys were similar.

A few attendances (11 out of 190 ) were made by more disabled ("non-walking") patients. The study was not primarily concerned with these but their fate deserves to be recorded. They were carried in ambulances manned by two men (standard double-

TABLE II-Time spent by Patients waiting at Home and travelling to and from Physical Treatment Centre during First Survey. Numbers are Percentages of Patients

\begin{tabular}{|c|c|c|c|c|c|c|}
\hline \multirow{2}{*}{ Time in Minutes } & \multicolumn{2}{|c|}{ Waiting at Home } & \multicolumn{2}{|c|}{ Travelling } & \multicolumn{2}{|c|}{ Waiting at Centre } \\
\hline & a.m. & p.m. & a.m. & p.m. & a.m. & p.m. \\
\hline $\begin{array}{l}<30 \\
30-59 \\
60-89 \\
90-119 \\
\geqslant 120\end{array}$ & $\left.\begin{array}{r}36 \\
31 \\
8 \\
21 \\
4\end{array}\right\} 33$ & $\left.\begin{array}{l}17 \\
26 \\
33 \\
17 \\
7\end{array}\right\} 57$ & $\left.\begin{array}{c}17 \\
47 \\
26 \\
7 \\
3\end{array}\right\} 36$ & $\left.\begin{array}{r}7 \\
22 \\
48 \\
18 \\
5\end{array}\right\} 71$ & $\left.\begin{array}{c}16 \\
40 \\
34 \\
7 \\
3\end{array}\right\} 44$ & $\left.\begin{array}{c}51 \\
34 \\
8 \\
5 \\
2\end{array}\right\} 15$ \\
\hline Total & 100 & 100 & 100 & 100 & 100 & 100 \\
\hline
\end{tabular}


handed vehicles) and their collections were fitted in with other duties. It was thus quite impossible to predict from day to day when these patients would arrive and when they would be taken home. These patients spent much longer waiting than the majority, and for half an hour of treatment many of them had what could amount to an all-day wait. Typically a patient was told to be ready by 8.30 a.m. but was not picked up until 10.45 a.m., and then after treatment he would often have to wait until the early afternoon before the ambulance returned to take him home. A total journey time, with waiting, of eight hours was by no means exceptional.

\section{Discussion}

The Harrow Physical Treatment Centre is due to be closed shortly and the work transferred to a new, purpose-built rehabilitation centre within a district general hospital complex. The quality of service that the new centre will be able to provide will largely depend on the ease with which patients can be transported. We hoped that a review of the present system would help planning transport arrangements for the new centre. $^{2}$

From the onset of the study it was clear that there were two major local advantages. Firstly, the catchment area was urban and compact $(84 \%$ of the patients lived within 3 miles $(4.8 \mathrm{~km})$ of the centre) and, secondly, the ambulance and driver were reserved solely for the use of the centre. The driver therefore had detailed local knowledge and was not withdrawn for other, conflicting duties. A major disadvantage uncovered during the study was the lack of the person with sole responsibility for the co-ordination of the ordering and cancelling of ambulances. When the the first survey was completed in 1972 the findings were discussed with the senior members of the local ambulance service. They reiterated the importance of a clearly-defined catchment area and suggested that they should be consulted in any projected alteration of its boundaries, as they had detailed local knowledge of normal traffic flow and prevailing traffic conditions. It was hoped to continue the practice of reserving a single-handed ambulance exclusively for the use of the centre and the procedure for ordering and cancelling transport was altered so that it became the responsibility of one person.

The second survey showed shorter overall times away from home than the first, with significantly shorter times spent travelling and waiting at the centre. These findings may be due to one or more of several possible differences between the circumstances under which the two surveys were carried out; one of these possibilities is that the discussions with the ambulance staff after the first survey may have been responsible. Nevertheless, whatever the reasons overall times remained long.

A quarter of the patients were treated three or more times a week and over half were over 65 years of age. For these elderly patients, often with dependent spouses, frequent outpatient physiotherapy sessions with the concomitant early starts and frustrating waits can be very disturbing.

Another method of transporting patients to the centre would be to use the hopital car service. The service provided would then be more individual and would relieve pressure on the already overburdened ambulance resources. Major disadvantages of the use of this voluntary service are the problems of organization and flexibility, but a study in North Berkshire ${ }^{3}$ has shown that these drawbacks can be overcome, albeit in a rural area.

The provision of domiciliary physiotherapy would greatly reduce the need for transport. This method has been tried experimentally on a small scale in rural Oxfordshire 4 but apparently not in urban surroundings. The value of this type of a service may well be greater than is immediately apparent. ${ }^{5}$ Though the therapist could not treat as many patients in a given time as she could in the physiotherapy department, the patients themselves would probably get more benefit from treatment uncomplicated by the fatigue and anxiety of travelling to the treatment department.

If patients are to be transported by ambulance to the treatment centre, one way of easing the load on the ambulance service is to give senior therapists the authority to modify a patient's transport requirements. During the first survey we found that many patients had improved during treatment so that they no longer required ambulance transport or, in some cases, further treatment. But under the then existing procedures transport arrangements could be reviewed only by a doctor, who saw the patients at the end of their treatment course. Allowing a senior remedial therapist to perform this task should help to ensure a more economic use of the ambulance service.

For many patients outpatient physiotherapy entails not only the actual treatment but also much time spent travelling to and from the treatment centre. The disturbance to the social life of and elderly patient is an important side effect of this type of therapy. For some conditions the effectiveness of outpatient physiotherapy is not proved. Then doctors ordering it should remember that it may be merely a potentially socially disruptive placebo.

We should like to thank Dr. T. W. Meade for his help and encouragement and Miss Frances Fairweather for her secretarial services.

\section{References}

${ }^{1}$ Ministry of Health, Out-patient Departments and the Ambulance Service. Hospital O. \& M. Service Reports, No. 8. London, H.M.S.O., 1964.

2 Department of Health and Social Security, Management Arrangements for the Reorganised National Health Serivice. London, H.M.S.O., 1972.

${ }^{3}$ Nuffield Operational Research Unit, A Study of the Organisation of the Amulance Service in North Berkshire. Department of Applied Statistics, The University, Reading, 1969.

4 Personal communication.

5 Compton, A., Physiotherapy, 59, 75. 